Historic, Archive Document

Do not assume content reflects current scientific knowledge, policies, or practices 



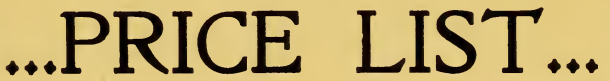

F. O. B., SAN'TA CLARA, CAI.

For Strictly ....

\section{HIGH-GRADE SEEDS}

\section{J. M. KIMBERLIN \& CO. INCOR PORATED}

\section{SEED GROWERS}

SANTA CLARA,

CALIFORNIA

OFFICERS

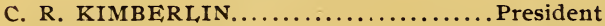
L. M. KIMBERLIN ........ Secretary and Manager H. V. KIMBERI,IN................. Treasurer 



\section{J. M. KIMBERLIN \& $\mathrm{C}$. (INCORPORATED)}

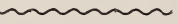

When ordering, please put prices on your order.

Terms: June I, I9o or 5 per cent. discount for cash (30 days).

All seeds sold F. O. B. Santa Clara, Cal.

J. M. KIMBERLIN \& CO.

\section{ONION}

Yellow Danvers

Yellow Strasburg...............................

Yellow Globe Danvers.

Yellow Prizetaker.................

Ohio Yellow. Globe.

Michigan Yellow Globe 


\section{ONION-CONTINUED}

Southport Yellow Globe.

Australian Brown

Red Wethersfield

Extra Early Red Flat.

Southport Red Globe

Early Red Bermuda

Gregory's Early Red Globe.

White Portugal

Philadelphia Silverskin

Southport White Globe.

Mammoth Silver King...

Early White Pearl.

New White Queen 


\section{BEET}

Long Red Mangel

Long Blood.

Early Blood Turnip

Early Eclipse...

Dark Red Egyptian

\section{CARROT}

Chantenay Half Long.

Danvers Half Long........................

Early Scarlet Horn.

Improved Orange Long..

Nantes Half Long............................

White. Belgian 


\section{LETTUCE}

All Season's (Black Seed)

American Gathering....

All the Year Round.

Big Boston (Henderson)

Black Seeded Simpson

Black Seeded Tennisball.

Black Seeded Butter.

Black Seeded Satisfaction.

Black Seeded St. Louis Forcing.

Boston Market.

Boston Curled.

Brown Dutch.

Butter Cup.

California Cream Butter.

Crisp as Ice

Deacon (Improved).

Denver Market

Drumbead or Malta 


\section{IETTUCE-CONTINUED}

Early Curled Simpson

Early White Cabbage.

Grand Rapids

Green Fringe.

Giant White Cos.

Hubbard's Market.

Hanson Improved

Henderson's Immensity...

Hard Head Forcing (Burpee's)

Iceberg...

Maximum or Queen of Lettuce.

Marblehead Mammoth

Market Gardener's Private Stock.

New York (Henderson's)

Oak Leaf.

Passion

Perpetual 


\section{LETTUCE-CONTINUED}

Philadelphia Butter.

Prize Head

Paris White Cos

Royal Summer Cabbage

Silver Ball.

Shotwell's Brown

Sensation

Silesia Early Curled....

Stonehead Golden Yellow.

Salamander

Tomhannock.

Trocadero Cabbage.

Tilton's White Star.

Trianon Cos or (Celery)

White Seeded Tennisball...

Wonderfui

White Paris Cos (Self-folding.

Yellow Seeded Butter. 


\section{LETTUCE-CONCLUDED}

Lapps Best Black Seed Butter. (1)

$\ldots \ldots \ldots \ldots \ldots \ldots \ldots \ldots \ldots \ldots \ldots \ldots$

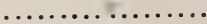

$\ldots \ldots$

$\ldots$
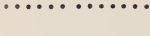

$\cdots \cdots$

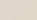

$\cdots \cdots$

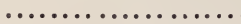

$\ldots \ldots \ldots$

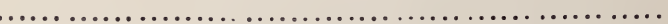

\section{LEEK}

Carentan

Large London Flag.

Rouen 


\section{RADISH}

Becket's Chartier.

Chinese Stump Rooted

Deep Scarlet Turnip

Earliest White Turnip...

French Breakfast

Glass or Cincinnati Market.

Half Long Deep Scarlet.

Icicle (New Long White).

Long Black Spanish

Long Scarlet Short Tup.

Long White Vienna

Round Black Spanish..

Rosy Gem White Tipped

Scarlet Glube

Scarlet Olive Shaped...

Scarlet Turnip......
Triumpl, Striped.

White Strasburg. 


\section{RADISH-CONCLUDED}

White Tipped Scarlet Turnip...............

White Summer Turnip.......................

White Box..................................

White Olive Shaped

White Celestial.

Wood's Early Frame.

Early Scarlet Button.

\section{SALSIFY}

Long White.

Mammoth Sandwich Island... 


\section{CELERY}

Boston Market..

Golden Self-Blanching

Giant Pascal

Golden Hearted Dwarf..

Heartwell Perfection

Henderson New Rose

Henderson White Plume

Henderson's Half Dwarf.

Pink Plume.

Seasoning or Flavoring..

\section{ENDIVE}

Broad Leaved.

Green Curled.

Moss Curled.

White Curled 


